\title{
Retraction Note to: An infectious molecular clone in early infection with HIV-1 subtype CRF01_AE strains: construction and biological properties
}

\author{
Hong-Wei Wang ${ }^{1} \cdot$ Bin $\mathrm{Zhu}^{2} \cdot \mathrm{Li}$-Juan $\mathrm{Hou}^{1} \cdot$ Guang-Jian $\mathrm{Lu}^{3} \cdot$ \\ Lu-Yang Jiao ${ }^{3} \cdot$ Bao-Sheng Shen ${ }^{1}$
}

Published online: 18 August 2015

(C) Springer Science+Business Media Dordrecht 2015

\section{Retraction Note to: Mol Biol Rep (2015) 42:329-336 \\ DOI 10.1007/s11033-014-3754-9}

The Publisher and Editor retract this article in accordance with the recommendations of the Committee on Publica tion Ethics (COPE). After a thorough investigation we have strong reason to believe that the peer review process was compromised.

The online version of the original article can be found under doi:10.1007/s11033-014-3754-9.

Bao-Sheng Shen

shenbaosheng1029@126.com

1 The First Department of Infectious, The First Affiliated Hospital of Xinxiang Medical University, Weihui 453100, China

2 The Second Department of Infectious, The First Affiliated Hospital of Xinxiang Medical University, Weihui 453100, China

3 Department of Inspection, The First Affiliated Hospital of Xinxiang Medical University, Weihui 453100, China 